\title{
Characteristics and Adverse Outcomes of Chinese Adolescent Pregnancy Between 2012 and 2019: An Observational Study of 438 Health Facilities
}

\author{
Yanxia Xie \\ West China Second University Hospital of Sichuan University \\ Xiaodong Wang \\ West China Second University Hospital of Sichuan University \\ Yi Mu \\ West China Second University Hospital of Sichuan University \\ Zheng Liu \\ West China Second University Hospital of Sichuan University \\ Yanping Wang \\ West China Second University Hospital of Sichuan University \\ Xiaohong Li \\ West China Second University Hospital of Sichuan University \\ Li Dai \\ West China Second University Hospital of Sichuan University \\ Qi Li \\ West China Second University Hospital of Sichuan University \\ Mingrong Li \\ West China Second University Hospital of Sichuan University \\ Peiran Chen \\ West China Second University Hospital of Sichuan University \\ Jun Zhu \\ West China Second University Hospital of Sichuan University \\ Juan Liang ( $\nabla$ liangjuan@scu.edu.cn) \\ West China Second University Hospital of Sichuan University
}

\section{Research Article}

Keywords: Adolescent pregnancy, epidemiology, adverse pregnancy outcomes, maternal near miss, gestational age

Posted Date: March 2nd, 2021

DOl: https://doi.org/10.21203/rs.3.rs-253568/v1

License: @ (i) This work is licensed under a Creative Commons Attribution 4.0 International License. Read Full License 


\section{Abstract}

We aimed to describes characteristic of adolescent pregnancy, determines its effect on adverse maternal and perinatal outcomes and explores whether that association varies with gestational age with the goal of proposing specific recommendations for adolescent health in China. 2,366,559 women aged 10-24 years who had singleton pregnancies between 2012 and 2019 from 438 hospitals were included in the study. Adolescent pregnancy was defined as younger than 20 years of age. We used multivariable logistic regression to estimate the effect. Women aged 20-24 years served as the reference group in all analyses. The proportion of rural girls with adolescent pregnancies rebounded after 2015 despite common-law marriage in rural areas have improved. Higher risks of eclampsia (adjusted odds ratio (aOR) 1.87, 95\% confidence interval ( $\mathrm{Cl})$ 1.57 2.23), severe anaemia (aOR 1.18, 95\% Cl 1.09 1.28), maternal near miss (aOR 1.24, 95\% Cl 1.12 1.37), and small-for-gestational-age (aOR 1.30, 95\% Cl 1.28 1.33) were observed when gestational age was > 37 weeks. Adolescent pregnancy was independently associated with increased risks of other perinatal outcomes. Further implementation of pregnancy prevention strategies and improved health care interventions are needed to reduce adolescent fertility and to avoid adverse fertility outcomes among adolescent women in China at a time when adolescent fertility is rebounding.

\section{Introduction}

Adolescent pregnancy usually refers to intended or unintended pregnancy in women within the ages of 10-19 years ${ }^{1}$. Babies born to adolescent mothers account for approximately $11 \%$ of all births worldwide, with $90 \%$ occurring in low-income countries ${ }^{2}$. Some important factors have influenced adolescent pregnancy in recent decades in China, such as the marriage market, the phenomenon of cohabitation, and unprotected sex ${ }^{3-5}$. A recent study indicated that although China's total fertility rate remains far less than replacement, the age-specific fertility rate for the 15- to 19-year age group rebounded from 6.0 births per 1000 in 2000 to 9.2 births per 1000 in $2015^{5}$. Adolescent pregnancy contributes to maternal mortality, perinatal and infant mortality, and the vicious cycle of ill health and poverty ${ }^{2}$. It has a long-term impact on the physical and mental health of adolescents and continues to be a challenging public health issue in China and some low-income countries.

Studies from high- or low-income countries have consistently reported that adolescent pregnancies are at increased risk for some adverse maternal and perinatal outcomes, such as eclampsia ${ }^{6,7}$, puerperal endometritis ${ }^{6}$, stillbirth ${ }^{8}$, low birth weight (LBW $)^{9,10}$, preterm delivery ${ }^{8-11}$, small-for-gestation-age $(\text { SGA })^{10}$, and intra-hospital early neonatal death ${ }^{6,8}$. Gestational age is the major determinant of maternal and neonatal health, but the association between the range of gestational age and the risk of adolescent pregnancies has rarely been investigated ${ }^{12,13}$. Although Hebei Province reported an adolescent pregnancy effect on some adverse maternal and perinatal outcomes, ${ }^{8}$, this study was a partial analysis conducted prior to 2017 , and the data from only one province were inadequately representative of China. To date, no studies have reported data representing all of China.

In this research, based on China's National Maternal Near Miss Surveillance System (NMNMSS), data were collected from 2012 to 2019 covering 30 provinces of mainland China. The objective of this large hospital-based study was to describe the distribution of adolescent pregnancy, to determine the adolescent pregnancy effect on adverse maternal and perinatal outcomes and to explore whether that association varies with gestational age with the goal of proposing specific recommendations for adolescent health in China.

\section{Methods}

\section{Data sources}

Individual maternal data were collected through NMNMSS from 1 January 2012 to 31 December 2019. The NMNMSS was established in 2010 and covers 441 member hospitals that treat more than 1000 deliveries annually. The member hospitals are located in 326 districts or counties throughout 30 provinces in mainland China, excluding Tibet. The NMNMSS collects the sociodemographic and obstetric information of pregnant and postpartum women from the obstetric departments of surveillance hospitals. The collected data include the name and code of the hospital, date of delivery, number of antenatal visits, maternal educational and marital status, mother's date of birth, gestational age at delivery or at termination of pregnancy, mode of delivery, parity, and number of foetuses. The detailed sample methods have been described elsewhere ${ }^{14-16}$. The data provided to us were de-identified.

Data used in our study is not publicly available, and all methods were performed in accordance with the relevant guidelines and regulations.

\section{Definition}

Maternal age was defined as the age of the mother in completed years at the time of delivery. All women aged 10-24 years who had singleton pregnancies delivered in 438 hospitals (3 hospitals were excluded because data were not reported since 2012) between 1 January 2012 and 31 December 2019 in the NMNMSS were included in the present study. Maternal age was categorized into 3 groups: less than 18, 18-19, and 20-24 years. Since women aged 20-24 years had the lowest risk of adverse outcomes, they served as the reference group in all analyses.

Maternal outcomes included maternal near miss (MNM) and some of the most common maternal complications in China, including antepartum haemorrhage, postpartum haemorrhage, preeclampsia, eclampsia, HELLP syndrome, diabetes (both pre-existing and gestational), premature rupture of membranes (PROM) and severe anaemia (haemoglobin concentration $<70 \mathrm{~g} / \mathrm{L}$, with the definition excluding postpartum haemorrhage). The definitions and criteria of maternal death and MNM were fully consistent with the recommendations from the $\mathrm{WHO}^{17}$. Antepartum haemorrhage, including uterine rupture, placenta previa, placenta accreta, abruptio placenta or other types, occurred during or before the second stage of labour. Postpartum haemorrhage, including soft birth canal lacerations, uterine atony, retained placenta or other types, was defined as obstetric haemorrhage greater than $500 \mathrm{ml}$ during vaginal delivery or $1000 \mathrm{ml}$ during caesarean section and occurred in or after the third stage of labour ${ }^{18}$. 
Perinatal outcomes were restricted to live births at 28 gestational weeks or later or to a birthweight of more than 1000 grams, in accordance with the definition of third-trimester stillbirth from the $\mathrm{WHO}^{19}$. Gestational age in China is generally ascertained on the basis of the last menstrual period or the ultrasound examination when the date of the last menstrual period is not known ${ }^{20}$. Gestational age was categorized into 3 groups: $<28 \mathrm{w}, 28-36 \mathrm{w}$, and $>=37 \mathrm{w}$. Perinatal outcomes of interest in this study were stillbirth, preterm birth (less than 37 gestational weeks), SGA (birth weight less than the 10th percentile for gestational age $)^{21}$, and low birth weight (less than 2500 grams).

The mode of delivery was defined into 4 groups: miscarriage or abortion, termination of pregnancy (TOP), vaginal delivery, and caesarean section. Miscarriage or abortion was defined as loss at a gestational age less than 28 weeks and included miscarriage and induced abortion. TOP referred to induced labour at more than 28 weeks of gestation due to foetal or maternal causes.

The usual definitions of region, marital status, number of antenatal care visits, maternal educational status, caesarean history and parity were used, as detailed elsewhere. Based on the hospitals' locations, we classified regions as north, northeast, east, south, central, southwest, and northwest China. The hospital level was defined based on a comprehensive standard that includes the number of beds in the hospital and the medical staff, clinical department categories, type and quantity of medical equipment and funding of the hospital ${ }^{20}$. Level 1 represents the smallest hospitals, and level 3 represents the largest hospitals.

\section{Statistical analysis}

We first describe the distribution of demographic characteristics, prenatal care, gestational age and delivery outcome by maternal age group. The incidence of adverse maternal outcomes and perinatal outcomes was calculated for each maternal age group. The $p$ values for trends were determined by logistic regression.

The adjusted odds ratios (aORs) along with 95\% confidence intervals (Cls) associated with adolescent pregnancies, with reference to the 20- to 24 -year-old group, were derived through multivariable logistic regression models with adjustment for potential confounders. Potential confounding variables considered for adjustment in the regression models included the clustering of births within hospitals, region, birth location (urban/rural), hospital level, year, and the mother's education status, marital status, caesarean history and parity. To explore whether the association risk of adolescent pregnancies varies between different gestational ages, we additionally conducted a subgroup analysis ( $<28 \mathrm{w}, 28-36 \mathrm{w}$, and $>=37 \mathrm{w})$. The results of the subgroup analysis are detailed further in the Additional file 1.

All statistical calculations were performed using Stata software, version 16.0 (Stata Corp LP., College Station, United States of America). A 2-sided $p$ value of less than 0.05 was considered statistically significant.

\section{Ethics approval and consent to participate}

Ethical approval for the NMNMSS was provided by the Ethics Committee of West China Second University Hospital, Sichuan University, China (protocol ID, 2012008). Informed consent from the patient was waived from the Ethics Committee, as the data used in this study were obtained from a national routine surveillance system established by the government. Data use was authorized by the National Health Commission, and data provided to us were de-identified.

\section{Results}

\section{Characteristics of adolescent pregnancy}

Over the 8-year period, $12,184,452$ pregnancies were recorded in our database, of which we excluded 9,182,421 mothers older than 24 years, 30,866 multiple pregnancies, 563,584 for whom maternal age was missing, and 41,022 for whom information on the number of foetuses was missing. The remaining $2,366,559$ women constituted the study population, of whom 283,746 were adolescents. Overall, adolescents accounted for $2.48 \%$ of all deliveries in our database.

There were 2,974 (0.13\%), 7,847 (0.33\%), 20,824 (0.88\%), 44,462 (1.88\%), 79,214 (3.35\%), 128,425 (5.43\%), and 2,082,813 (88.01\%) pregnancies aged <=14, 15, $16,17,18,19$ and $20-24$ years, respectively. Adolescent pregnancy is most common in the economically underdeveloped western region, followed by the central region; it is least common in the eastern region, which has the best economic development level. In each region, the distribution is larger in rural areas than in urban areas. A total of $68.53 \%$ of adolescent pregnancies were from rural areas. The proportion of rural girls with adolescent pregnancies rebounded after 2015 (Figure 1a). Common-law marriage in rural areas have improved among adolescent pregnancies, but they are still more common than urban areas. In both urban and rural areas, the proportion of unmarried adolescent pregnancies continued to increase in 2012-2019, and unmarried childbearing was more common in urban areas (Figure 1b). Moreover, compared with women aged 20-24 years, adolescent mothers were more likely to be unmarried and nulliparous and to have a lower educational level or inadequate prenatal care during pregnancy (Table 1).

The incidence of adverse maternal and perinatal outcomes, such as miscarriage or abortion, TOP, puerperal infection, eclampsia, HELLP syndrome, severe anaemia, maternal near miss, stillbirth, preterm delivery, LBW, SGA, and early neonatal death, was higher in adolescent pregnancies. These outcomes consistently increased with decreasing maternal age and were consistently highest among mothers aged less than 15 years. However, the incidence of antepartum haemorrhage, postpartum haemorrhage, gestational diabetes mellitus (GDM), and PROM increased with increasing maternal age (Table 2).

Adolescent pregnancy effect on adverse maternal and perinatal outcomes 
Adjusted ORs and 95\% Cls for the association between maternal age and adverse maternal outcome are shown in Table 3. Compared with mothers aged 2024 years, adolescent mothers had higher risks of TOP, eclampsia, HELLP syndrome, severe anaemia, MNM, stillbirth, preterm delivery, LBW, SGA, and early neonatal death, and the youngest mothers faced the highest risks. The risks of antepartum haemorrhage, postpartum haemorrhage, preeclampsia, GDM, and maternal death during hospitalization were significantly lower in adolescent mothers than in mothers 20-24 years old. In addition, the associations between minor mothers ( $<18$ years) and antepartum and postpartum haemorrhage were nonsignificant.

Furthermore, we found that the risks of antepartum haemorrhage and postpartum haemorrhage were significantly lower in adolescent mothers when the gestational age was 28-36 weeks or >=37 weeks. The same results were found when adolescents were divided into $<18$ years and 18-19 years. Compared with mothers aged 20 to 24 years, adolescent mothers had higher risks of eclampsia, severe anaemia, and MNM when the gestational age was greater than 37 weeks; the youngest mothers faced higher risks, whereas mothers aged 18 to 19 had smaller increases in risks. Nevertheless, adolescent mothers are less likely to have intra-hospital maternal deaths with a gestational age of 28-36 weeks (Figure 2₫Additional table 1). Moreover, adolescent mothers are at greater risks of stillbirth and LBW regardless of gestational age; the younger their age is, the greater the risk. Similar results were found for the risk of SGA among adolescent mothers when gestational age was greater than 37 weeks. However, at 28-36 weeks of gestation, adolescent mothers younger than 18 years old were less likely to have SGA but had an increased risk of intra-hospital early neonatal death (Figure 3ロAdditional table 2).

\section{Discussion}

Using a large hospital-based dataset, we described the distribution and pregnancy outcomes among adolescent mothers in 30 provinces of mainland China. Adolescent pregnancy is mainly distributed in economically underdeveloped areas and is more common in rural areas (68.53\%), especially in western rural areas (29.05\%). The proportion of rural girls with adolescent pregnancies rebounded after 2015, and the proportion of unmarried people is increasing year by year. The adolescent pregnancy effect on some adverse maternal and perinatal outcomes varies with gestational age. Higher risks of eclampsia, severe anaemia, and MNM were observed at gestational age greater than 37 weeks, and lower risks of antepartum haemorrhage and postpartum haemorrhage were observed at gestational age >= 28 weeks among adolescent mothers compared with mothers aged 20-24 years. The risk of intra-hospital maternal deaths was significantly lower among adolescents than non-adolescent mothers when the gestational age was 28-36 weeks. Our results further showed that adolescent pregnancy was independently associated with increased risks of stillbirth, preterm delivery, low birth weight, and SGA and an increased risk of intra-hospital early neonatal death among non-adult mothers when the gestational age was 28-36 weeks. In addition, we observed higher risks of adverse perinatal outcomes with decreasing maternal age as well as partial adverse maternal outcomes.

Early marriage and adolescent fertility rates were included in the 12 key indicators of adolescent health and well-being proposed by the 2016 Lancet Commission on Adolescent Health and Wellbeing 22 . The new "Marriage Law of the People's Republic of China" promulgated in 1981 stipulated that the minimum marriage age for women was 20 years old, which, to a certain extent, restricted the occurrence of early marriage and childbearing behaviours among Chinese female adolescents. The open-door policy and economic reforms of the 1980s not only injected vitality into economic development but also considerably changed social norms and values pertaining to love and marriage. Attitudes towards sex have become more open, while the negative consequences of early sexual intercourse have become issues of health and social concern ${ }^{23,24}$. There are inherent differences between urban and rural areas; for example, compared to urban areas, the overall level of the rural economy, education and social customs are relatively poorer or more conservative ${ }^{23}$. The data of our study showed that the proportion of the common-law marriage decreased from 2012 to 2019 , but it continued among adolescents, especially in areas with low levels of economic development, such as rural areas. The proportion of unmarried adolescent pregnancies is increasing year by year in both urban and rural areas, and unmarried childbearing is more common in urban areas.

For some adolescent women, pregnancy and childbirth are planned and wanted, but for many others, they are not. Several factors contribute to unplanned and unwanted pregnancies in adolescents. Over the past 20 years, sexual activity outside marriage and high-risk sexual behaviours have increased among Chinese adolescents, contributing to more unintended pregnancies ${ }^{25}$. The proportion of unmarried adolescent pregnancies in our study increased from $21.5 \%$ in 2012 to $32.3 \%$ in 2019 . In addition, a survey of adolescent sexual and reproductive health in China showed that $21.4 \%$ of unmarried young women aged $15-24$ years did not use contraception during their most recent episode of intercourse 5 . Some do not know how to avoid pregnancy, while others are unable to obtain condoms and contraceptives. Adolescents may be unable to refuse unwanted sex or to resist coerced sex ${ }^{26}$. Even in the context of reform and opening up, conservative taboos about sex in China, especially in rural areas, are still deeply rooted. Sex education and female self-protection awareness are lacking ${ }^{27}$. In addition, society maintains a contemptuous attitude towards unmarried pregnancy; coupled with the age limit of the marriage law and the custom of early marriage and early childbearing in rural areas, this contributes to the existence of common-law marriage. In our study, girls under the legal age of marriage in rural areas mostly had common-law marriages. They may be under pressure to marry and to bear children early, and they may have limited educational and employment prospects. Unmarried pregnant adolescents, mainly in urban areas (urban $22.21 \%$ vs. rural $16.5 \%$ ), often use abortion or induction of labour to terminate their pregnancy, and the miscarriage/abortion or TOP rates of adolescent pregnancies increased from $9.17 \%$ to $13.38 \%$ during our study period. Failure to complete school, lack of occupation, lack of income and social prejudice might explain why adolescents have higher rates of miscarriage or abortion and TOP, and the youngest mothers (<18 years old) face the highest risks of TOP compared with mothers aged 20 to 24 years. Moreover, adolescents who become pregnant are less likely than adults to be able to obtain legal and safe abortions to terminate their pregnancies.

Adolescents, especially young adolescents, are still in the process of puberty growth and development. They do not have the ability to live independently, and they are not physically or psychologically ready for pregnancy. Premature pregnancy has adverse effects on health $1,2,6-8,10,11,19,22,28-30$. Our study demonstrated that higher risks of eclampsia, severe anaemia, and MNM were observed at a gestational age greater than 37 weeks among adolescent mothers compared with mothers aged 20-24 years. Fear of public condemnation and limited access to skilled prenatal care, poor nutritional level and a lack of prevention and treatment for hypertensive disorders, anaemia, or other complications during the early and second trimesters among adolescents could be 
reasonable explanations for the high risk of eclampsia, severe anaemia, and MNM in the third trimester. In addition, low caloric intake as well as increased iron requirements for red blood cell expansion during adolescence may contribute to a high risk of severe anaemia among adolescent mothers ${ }^{31}$.

Studies have reported that adolescents aged 15-19 years are twice as likely to die during pregnancy or childbirth as women over 20 years of age, and adolescents under 15 years of age are five times more likely to die during pregnancy or childbirth ${ }^{10,32}$. We found that MMR during hospitalization in adolescent pregnancy was higher than that for mothers aged 20-24 (8.1 per 100000 women vs. 7.4 per 100000 women). However, adolescent pregnancy was not a risk factor for MMR during hospitalization after adjusting for confounding factors. Moreover, compared with adult pregnant women (aged 20-24 years), adolescent pregnancy was a protective factor for maternal death during hospitalization when the gestational age was $28-36$ weeks. The pregnancy risk assessment for pregnant women in China is divided into low risk, general risk, higher risk, highest risk, and pregnant women with infectious diseases. Since young pregnant women ( $<=18$ years old) are included in the general risk for management during pregnancy and childbirth, effective management measures may be one of the reasons for the reduction in the risk of maternal death. On the other hand, a higher risk of MNM was observed among adolescent mothers. However, a series of rescue systems for maternal near miss have been established by medical institutions in China in recent years. If a critical situation occurs maternally, they can be sent to the treatment centre hospital in time through this system; this has effectively prevented most maternal near miss situations from developing into maternal deaths.

In terms of adverse perinatal outcomes, consistent with previous studies ${ }^{6-8,10,11}$, We found that compared with adult pregnant women, adolescent mothers had an increased risk of stillbirth, preterm birth, SGA, and low-birthweight, and the degree of risk decreased with age. We found that compared with adult pregnant women, adolescent mothers had an increased risk of stillbirth, preterm birth, SGA, and low-birthweight, and the degree of risk decreased with age. The theory that fetuses and mothers compete for nutrition is a common explanation for why infants born to adolescent mothers may be more prone to low low birthweight ${ }^{1,33}$. A surge in leptin in late pregnancy may block fat breakdown, increase the use of glucose for maternal growth, and reduce the energy needed for fetal growth ${ }^{33}$. In addition, the production of glycine, an amino acid needed for foetal growth and development, may be affected in young mothers. ${ }^{34}$. Micronutrient deficiencies may be another biological pathway that may affect fetal growth ${ }^{30}$. Previous studies have also shown that a short cervix ( $<=25$ $\mathrm{mm}$ ) and small uterine volume increases the risk of preterm birth, the mothers in adolescence may be more common ${ }^{28,35,36}$. Furthermore, depression and stress-related pathway may mediate adverse consequences, for example, preterm birth (e.g., by stimulating the release of placenta corticotropin releasing hormone) $)^{37}$.

Previous studies of intra-hospital early neonatal mortality (IHENM) in adolescent pregnancy have yielded conflicting results. A multi-country study suggested that IHENM was not increased in infants born to adolescent mothers compared with infants born to mothers aged 20-24 ${ }^{6}$. However, data from Hebei Province reported that the risk of early neonatal death was increased in adolescent mothers compared with mothers who were 25-34 years old ${ }^{8}$. We observed a high risk of IHENM in general adolescent mothers, but after stratifying according to gestational age, a high risk was only observed in adolescents (younger than 18 years of age) whose gestational age was $28-36$ weeks. The higher rates of SGA and LBW in adolescent mothers aged $<18$ may explain this result.

Our study found higher risks of adverse outcomes among adolescent mothers, suggesting that adolescent pregnancy prevention is crucial. First, the government should take measures to further reduce the occurrence of marriage before the legal age. Early marriage ( $<18$ years) and sexual debut have been reported to be determinants of adolescent pregnancy ${ }^{2}$. Second, it is of vital importance to reduce teenage pregnancy by conducting a range of adolescenttargeted strategies, including expanding sexuality and health education, building life skills, retaining adolescents in school, reducing coerced sex among adolescents, and providing contraceptive counselling and service, which specifically meet the needs for modern contraception in sexually active unmarried girls ${ }^{29}$. Finally, for pregnant adolescents, it is necessary to reduce the occurrence of unsafe abortion; increase the use of skilled antenatal, childbirth and postnatal care; and offer and promote postpartum and post-abortion contraception through multiple home visits and/or clinic visits to reduce the adverse effects of pregnancy on adolescents' long-term health and to reduce their chances of second pregnancies.

There are also several limitations in this study. First, the vast majority of adolescent pregnant women were 18-19 years old, and the results were mainly based on older adolescent pregnant women. This is why we only subdivided age into less than 18 and 18-19. The estimation of adverse risks could be biased in this study. Second, our monitoring objects in the hospital were all pregnant women admitted to the hospital but did not include those who went only to the outpatient clinic. Adolescent mothers are more likely to seek outpatient services to terminate pregnancy. Third, to explore changes in the characteristics of adolescent pregnancy, the proportion ratio was used instead of the rate. Although the proportion ratio cannot describe the frequency or intensity, it can explain the proportion or distribution of the internal components. Moreover, it is likely that residual confounding exists in our analyses. The database did not contain information about smoking, drinking, weight gain during pregnancy or economic status. These confounding factors might affect adverse pregnancy outcomes.

\section{Conclusion}

Chinese adolescent pregnancy is mainly distributed in economically underdeveloped areas. The majority of adolescent pregnancies are likely to be commonlaw marriages from rural areas and to have inadequate prenatal care during pregnancy and poor education levels. The effect of adolescent pregnancies on some adverse maternal and perinatal outcomes varies with gestational age. Higher risks of adverse perinatal outcomes increase with decreasing maternal age, as do partial adverse maternal outcomes. These findings emphasize the importance of further implementation of pregnancy prevention strategies and improved health care interventions to reduce adolescent fertility and to avoid adverse fertility outcomes among adolescent women in China at a time when adolescent fertility is rebounding.

\section{Declarations}




\section{Acknowledgements}

The authors acknowledge the institutions and staff of the National Maternal Near Miss Surveillance System for data collection, data entry, and data verification.

\section{Authors' contributions}

All authors have contributed to the conducting of this study. JL and JZ designed the study with contribution from all authors. YX. and XW did the statistical analysis with support from XL. YM, XW, JL, and JZ prepared the first draft and all authors contributed to critical interpretation of the results and development of the report. All authors saw and approved the final version. All authors have read, and confirm that they meet, ICMJE criteria for authorship.

\section{Competing interests}

The authors have declared that no competing interests exist.

\section{Funding}

This study was supported by the National Key R\&D Program of China (No. 2019 YFC1005100 to Juan Liang), the National Health and Family Planning Commission of the People's Republic of China, the China Medical Board (grant number 11-065), WHO (Grant Number: CHN-12-MCN-004888), and UNICEF (2019EJH015). The funders had no role in the study design, data collection and analysis, decision to publish, or preparation of the manuscript.

\section{References}

1. Johnson, W. \& Moore, S. E. Adolescent pregnancy, nutrition, and health outcomes in low- and middle-income countries: what we know and what we don't know. Bjog 123, 1589-1592, doi:10.1111/1471-0528.13782 (2016).

2. Chandra-Mouli, V., Camacho, A. V. \& Michaud, P. A. WHO guidelines on preventing early pregnancy and poor reproductive outcomes among adolescents in developing countries. J Adolesc Health 52, 517-522, doi:10.1016/j.jadohealth.2013.03.002 (2013).

3. Li, J. et al. A review of contraceptive practices among married and unmarried women in China from 1982 to 2010. Eur J Contracept Reprod Health Care 18, 148-158, doi:10.3109/13625187.2013.776673 (2013).

4. Yu, C. et al. Young internal migrants' major health issues and health seeking barriers in Shanghai, China: a qualitative study. BMC Public Health 19, 336, doi:10.1186/s12889-019-6661-0 (2019).

5. Luo, D. et al. Chinese trends in adolescent marriage and fertility between 1990 and 2015: a systematic synthesis of national and subnational population data. Lancet Glob Health 8, e954-e964, doi:10.1016/s2214-109x(20)30130-3 (2020).

6. Ganchimeg, T. et al. Pregnancy and childbirth outcomes among adolescent mothers: a World Health Organization multicountry study. Bjog 121 Suppl 1, 40-48, doi:10.1111/1471-0528.12630 (2014).

7. Indarti, J. et al. Teenage Pregnancy: Obstetric and Perinatal Outcome in a Tertiary Centre in Indonesia. Obstet Gynecol Int 2020, 2787602, doi:10.1155/2020/2787602 (2020).

8. Zhang, T. et al. The adverse maternal and perinatal outcomes of adolescent pregnancy: a cross sectional study in Hebei, China. BMC Pregnancy Childbirth 20, 339, doi:10.1186/s12884-020-03022-7 (2020).

9. Chen, X. K. et al. Teenage pregnancy and adverse birth outcomes: a large population based retrospective cohort study. Int J Epidemio/36, 368-373, doi:10.1093/ije/dyl284 (2007).

10. Conde-Agudelo, A., Belizán, J. M. \& Lammers, C. Maternal-perinatal morbidity and mortality associated with adolescent pregnancy in Latin America: Cross-sectional study. Am J Obstet Gyneco/ 192, 342-349, doi:10.1016/j.ajog.2004.10.593 (2005).

11. Ogawa, K. et al. Association between adolescent pregnancy and adverse birth outcomes, a multicenter cross sectional Japanese study. Sci Rep 9 , 2365, doi:10.1038/s41598-019-38999-5 (2019).

12. Spong, C. Y. Defining "term" pregnancy: recommendations from the Defining "Term" Pregnancy Workgroup. Jama 309, 2445-2446, doi:10.1001/jama.2013.6235 (2013).

13. Bilsteen, J. F., Taylor-Robinson, D., Børch, K., Strandberg-Larsen, K. \& Nybo Andersen, A. M. Gestational Age and Socioeconomic Achievements in Young Adulthood: A Danish Population-Based Study. JAMA Netw Open 1, e186085, doi:10.1001/jamanetworkopen.2018.6085 (2018).

14. Mu, Y. et al. The national maternal near miss surveillance in China: A facility-based surveillance system covered 30 provinces. Medicine (Baltimore) 98 , e17679, doi:10.1097/md.0000000000017679 (2019).

15. Liang, J. et al. Relaxation of the one child policy and trends in caesarean section rates and birth outcomes in China between 2012 and 2016 : observational study of nearly seven million health facility births. Bmj 360, k817, doi:10.1136/bmj.k817 (2018).

16. Xiong, T. et al. Hypertensive disorders in pregnancy and stillbirth rates: a facility-based study in China. Bull World Health Organ 96, 531-539, doi:10.2471/blt.18.208447 (2018).

17. WH, O. Evaluating the quality of care for severe pregnancy complications: the WHO near-miss approach for maternal health. (2011).

18. Souza, J. P. et al. Moving beyond essential interventions for reduction of maternal mortality (the WHO Multicountry Survey on Maternal and Newborn Health): a cross-sectional study. Lancet 381, 1747-1755, doi:10.1016/s0140-6736(13)60686-8 (2013). 
19. Swaminathan, A., Fell, D. B., Regan, A., Walker, M. \& Corsi, D. J. Association between interpregnancy interval and subsequent stillbirth in 58 low-income and middle-income countries: a retrospective analysis using Demographic and Health Surveys. Lancet Glob Health 8, e113-e122, doi:10.1016/s2214$109 \times(19) 30458-9$ (2020).

20. Zhu, J. et al. Sociodemographic and obstetric characteristics of stillbirths in China: a census of nearly 4 million health facility births between 2012 and 2014. Lancet Glob Health 4, e109-118, doi:10.1016/s2214-109x(15)00271-5 (2016).

21. Dai, L. et al. Birth weight reference percentiles for Chinese. PLoS One 9, e104779, doi:10.1371/journal.pone.0104779 (2014).

22. Patton, G. C. et al. Our future: a Lancet commission on adolescent health and wellbeing. Lancet 387, 2423-2478, doi:10.1016/s0140-6736(16)00579-1 (2016).

23. Yu, J. Teenage sexual attitudes and behaviour in China: a literature review. Health Soc Care Community 20, 561-582, doi:10.1111/j.13652524.2011.01054.x (2012).

24. Zhang, K., Li, D., Li, H. \& Beck, E. J. Changing sexual attitudes and behaviour in China: implications for the spread of HIV and other sexually transmitted diseases. AIDS Care 11, 581-589, doi:10.1080/09540129947730 (1999).

25. Yu, X. M., Guo, S. J. \& Sun, Y. Y. Sexual behaviours and associated risks in Chinese young people: a meta-analysis. Sex Health 10, 424-433, doi:10.1071/sh12140 (2013).

26. Orchowski, L. M., Yusufov, M., Oesterle, D., Bogen, K. W. \& Zlotnick, C. Intimate Partner Violence and Coerced Unprotected Sex Among Young Women Attending Community College. Arch Sex Behav 49, 871-882, doi:10.1007/s10508-019-01537-5 (2020).

27. Burki, T. Sex education in China leaves young vulnerable to infection. Lancet Infect Dis 16, 26, doi:10.1016/s1473-3099(15)00494-6 (2016).

28. Gibbs, C. M., Wendt, A., Peters, S. \& Hogue, C. J. The impact of early age at first childbirth on maternal and infant health. Paediatr Perinat Epidemio/ 26 Suppl 1, 259-284, doi:10.1111/j.1365-3016.2012.01290.x (2012).

29. in WHO Recommendations on Adolescent Health (World Health Organization @ W World Health Organization 2017., 2017).

30. Baker, P. N. et al. A prospective study of micronutrient status in adolescent pregnancy. Am J Clin Nutr 89, 1114-1124, doi:10.3945/ajcn.2008.27097 (2009).

31. Scholl, T. O., Hediger, M. L. \& Belsky, D. H. Prenatal care and maternal health during adolescent pregnancy: a review and meta-analysis. $J$ Adolesc Health 15, 444-456, doi:10.1016/1054-139x(94)90491-k (1994).

32. in WHO Guidelines on Preventing Early Pregnancy and Poor Reproductive Health Outcomes Among Adolescents in Developing Countries (World Health Organization Copyright (c) World Health Organization 2011., 2011).

33. King, J. C. The risk of maternal nutritional depletion and poor outcomes increases in early or closely spaced pregnancies. J Nutr 133, 1732s-1736s, doi:10.1093/jn/133.5.1732S (2003).

34. Thame, M., Fletcher, H., Baker, T. \& Jahoor, F. Comparing the in vivo glycine fluxes of adolescent girls and adult women during early and late pregnancy. Br J Nutr 104, 498-502, doi:10.1017/s0007114510000784 (2010).

35. Gadelha Da Costa, A., Filho, F. M., Ferreira, A. C., Spara, P. \& Mauad, F. M. Uterine volume in adolescents. Ultrasound Med Bio/ 30, 7-10, doi:10.1016/j.ultrasmedbio.2003.09.009 (2004).

36. Stevens-Simon, C., Barrett, J., McGregor, J. A., French, J. \& Persutte, W. Short cervix: a cause of preterm delivery in young adolescents? J Matern Fetal Med 9, 342-347, doi:10.1002/1520-6661(200011/12)9:6<342::Aid-mfm1004>3.0.Co;2-d (2000).

37. Stevens-Simon, C., Beach, R. K. \& McGregor, J. A. Does incomplete growth and development predispose teenagers to preterm delivery? A template for research. J Perinato/ 22, 315-323, doi:10.1038/sj.jp.7210694 (2002).

\section{Tables}




\begin{tabular}{|c|c|c|c|c|c|c|c|c|}
\hline & \multirow[t]{2}{*}{ All adolescents } & \multicolumn{7}{|l|}{ Maternal age (y) } \\
\hline & & $<=14$ & 15 & 16 & 17 & 18 & 19 & $20-24$ \\
\hline $\begin{array}{l}\text { Total } \\
\text { pregnancies, } \\
\mathrm{n}\end{array}$ & 283,746 & 2,974 & 7,847 & 20,824 & 44,462 & 79,214 & 128,425 & $2,082,8^{-}$ \\
\hline \multicolumn{9}{|l|}{ Region } \\
\hline East urban & 17995(6.34\%) & $164(5.51 \%)$ & $431(5.49 \%)$ & $1183(5.68 \%)$ & $2539(5.71 \%)$ & $4935(6.23 \%)$ & $8743(6.81 \%)$ & 238761 \\
\hline East rural & $41341(14.57 \%)$ & $390(13.11 \%)$ & $1126(14.35 \%)$ & $3088(14.83 \%)$ & $6484(14.58 \%)$ & $11717(14.79 \%)$ & $18536(14.43 \%)$ & 294914 \\
\hline $\begin{array}{l}\text { Central } \\
\text { urban }\end{array}$ & $26184(9.23 \%)$ & $380(12.78 \%)$ & $710(9.05 \%)$ & $1810(8.69 \%)$ & $3739(8.41 \%)$ & $6967(8.80 \%)$ & 12578(9.79\%) & 315245 \\
\hline Central rural & $70690(24.91 \%)$ & $616(20.71 \%)$ & $1642(20.93 \%)$ & $4403(21.14 \%)$ & 10297(23.16\%) & $19676(24.84 \%)$ & $34056(26.52 \%)$ & 578921 \\
\hline West urban & $45117(15.90 \%)$ & $554(18.63 \%)$ & $1305(16.63 \%)$ & $3350(16.09 \%)$ & $7234(16.27 \%)$ & $12717(16.05 \%)$ & 19957(15.54\%) & 312875 \\
\hline West rural & $82419(29.05 \%)$ & $870(29.25 \%)$ & 2633(33.55\%) & 6990(33.57\%) & $14169(31.87 \%)$ & $23202(29.29 \%)$ & $34555(26.91 \%)$ & 342097 \\
\hline \multicolumn{9}{|l|}{$\begin{array}{l}\text { Antenatal } \\
\text { care }\end{array}$} \\
\hline None & $17623(6.21 \%)$ & $483(16.24 \%)$ & $999(12.73 \%)$ & $2052(9.85 \%)$ & $3293(7.41 \%)$ & $4781(6.04 \%)$ & $6015(4.68 \%)$ & 53966 \\
\hline $1 \sim 3$ & $52863(18.63 \%)$ & $855(28.75 \%)$ & $2077(26.47 \%)$ & $4969(23.86 \%)$ & $9320(20.96 \%)$ & 14584(18.41\%) & $21058(16.40 \%)$ & 217842 \\
\hline $4 \sim 6$ & $114560(40.37 \%)$ & $904(30.40 \%)$ & $2727(34.75 \%)$ & $7757(37.25 \%)$ & $17631(39.65 \%)$ & $32338(40.82 \%)$ & $53203(41.43 \%)$ & 765950 \\
\hline $7 \sim 9$ & $61673(21.74 \%)$ & $443(14.90 \%)$ & $1276(16.26 \%)$ & $3829(18.39 \%)$ & $9013(20.27 \%)$ & $17311(21.85 \%)$ & $29801(23.20 \%)$ & 573165 \\
\hline$>=10$ & $29383(10.36 \%)$ & $186(6.25 \%)$ & $538(6.86 \%)$ & $1629(7.82 \%)$ & $3967(8.92 \%)$ & $8043(10.15 \%)$ & $15020(11.70 \%)$ & 416833 \\
\hline Missing & $7644(2.69 \%)$ & $103(3.46 \%)$ & $230(2.93 \%)$ & $588(2.82 \%)$ & $1238(2.78 \%)$ & $2157(2.72)$ & $3328(2.59)$ & $55057(\stackrel{2}{2}$ \\
\hline \multicolumn{9}{|l|}{ Education } \\
\hline $\begin{array}{l}\text { College or } \\
\text { higher }\end{array}$ & $10377(3.66 \%)$ & $0(0.00 \%)$ & $0(0.00 \%)$ & $0(0.00 \%)$ & $1265(2.85 \%)$ & $2886(3.64 \%)$ & $6226(4.85 \%)$ & 378031 \\
\hline High school & $60933(21.47 \%)$ & $292(9.82 \%)$ & $1080(13.76 \%)$ & $3213(15.43 \%)$ & 7891(17.75\%) & $16749(21.14 \%)$ & $31708(24.69 \%)$ & 650070 \\
\hline $\begin{array}{l}\text { Middle } \\
\text { school }\end{array}$ & $185198(65.27 \%)$ & $1793(60.29 \%)$ & $5191(66.15 \%)$ & $14063(67.53 \%)$ & $30511(68.62 \%)$ & $52617(66.42 \%)$ & $81023(63.09 \%)$ & 959872 \\
\hline $\begin{array}{l}\text { Primary } \\
\text { school }\end{array}$ & 21933(7.73\%) & 592(19.91\%) & $1233(15.71 \%)$ & $2619(12.58 \%)$ & $4083(9.18 \%)$ & $5776(7.29 \%)$ & $7630(5.94 \%)$ & 63671( \\
\hline Illiteracy & $2362(0.83 \%)$ & $48(1.61 \%)$ & $92(1.17 \%)$ & $217(1.04 \%)$ & $416(0.94 \%)$ & $640(0.81 \%)$ & $949(0.74 \%)$ & $9029(0$. \\
\hline Missing & $2943(1.04 \%)$ & $249(8.37 \%)$ & $251(3.20 \%)$ & $712(3.42 \%)$ & $296(0.67 \%)$ & $546(0.69 \%)$ & $889(0.69 \%)$ & 22140 \\
\hline \multicolumn{9}{|l|}{$\begin{array}{l}\text { Marital } \\
\text { status }\end{array}$} \\
\hline Unmarried & $68678(24.20 \%)$ & $2974(100.00 \%)$ & 2926(37.29\%) & 6911(33.19\%) & $12768(28.72 \%)$ & $18680(23.58 \%)$ & $24419(19.01 \%)$ & $54822(2$ \\
\hline Married & 215018(75.78\%) & $0(0.00 \%)$ & $4919(62.69 \%)$ & $13908(66.79 \%)$ & $31689(71.27 \%)$ & 60514(76.39\%) & 103988(80.97\%) & 202759 \\
\hline Missing & $50(0.02 \%)$ & $0(0.00 \%)$ & $2(0.03 \%)$ & $5(0.02 \%)$ & $5(0.01 \%)$ & $20(0.03)$ & $18(0.01 \%)$ & $400(0.0$ \\
\hline \multicolumn{9}{|l|}{ Parity } \\
\hline Nulliparous & $248334(87.52 \%)$ & 2717(91.36\%) & 7354(93.72\%) & 19448(93.39\%) & 40559(91.22\%) & 69623(87.89\%) & 108633(84.59\%) & 155681 \\
\hline $\begin{array}{l}\text { Mutiparous } \\
\text { without scar }\end{array}$ & $29474(10.39 \%)$ & $200(6.72 \%)$ & $404(5.15 \%)$ & $1140(5.47 \%)$ & $3285(7.39 \%)$ & $8055(10.17 \%)$ & $16390(12.76 \%)$ & 393713 \\
\hline $\begin{array}{l}\text { Mutiparous } \\
\text { with scar }\end{array}$ & $5670(2.00 \%)$ & $54(1.82 \%)$ & $79(1.01 \%)$ & $216(1.04 \%)$ & $576(1.30 \%)$ & $1461(1.84 \%)$ & $3284(2.56 \%)$ & 129944 \\
\hline Missing & $268(0.09 \%)$ & $3(0.10 \%)$ & $10(0.13 \%)$ & $20(0.10 \%)$ & $42(0.09 \%)$ & $75(0.09 \%)$ & $118(0.09 \%)$ & $2346(0$. \\
\hline \multicolumn{9}{|l|}{$\begin{array}{l}\text { Gestational } \\
\text { weeks }\end{array}$} \\
\hline$<28$ & $24772(8.81 \%)$ & $700(23.92 \%)$ & $1430(18.47 \%)$ & $2905(14.14 \%)$ & $4533(10.31 \%)$ & $6644(8.46 \%)$ & $8560(6.72 \%)$ & $78241(\xi$ \\
\hline $28-36$ & 23433(8.34\%) & $411(14.05 \%)$ & $993(12.83 \%)$ & $2235(10.88 \%)$ & $4190(9.53 \%)$ & 6384(8.13\%) & $9220(7.24 \%)$ & 116556 \\
\hline$>=37$ & 232887(82.08\%) & $1815(61.03 \%)$ & $5318(67.77 \%)$ & $15411(74.01 \%)$ & $35230(79.24 \%)$ & 65470(82.65\%) & $109643(85.38 \%)$ & 187837 \\
\hline
\end{tabular}




\begin{tabular}{|c|c|c|c|c|c|c|c|c|}
\hline Missing & $2654(0.94 \%)$ & $48(1.61 \%)$ & $106(1.35 \%)$ & $273(1.31 \%)$ & $509(1.14 \%)$ & $716(0.90 \%)$ & $1002(0.78 \%)$ & $9644(0$. \\
\hline \multicolumn{9}{|l|}{$\begin{array}{l}\text { Delivery } \\
\text { outcome }\end{array}$} \\
\hline $\begin{array}{l}\text { Miscarriage } \\
\text { or abortion }\end{array}$ & $24149(8.51 \%)$ & $675(22.70 \%)$ & 1398(17.82\%) & $2825(13.57 \%)$ & $4418(9.94 \%)$ & $6461(8.16 \%)$ & $8372(6.52 \%)$ & 76553( \\
\hline TOP* & $1949(0.69 \%)$ & $98(3.30 \%)$ & $166(2.12 \%)$ & $282(1.35 \%)$ & $368(0.83 \%)$ & $465(0.59)$ & $570(0.44 \%)$ & $5796(0$. \\
\hline $\begin{array}{l}\text { Vaginal } \\
\text { delivery }\end{array}$ & 188392(66.39\%) & $1655(55.65 \%)$ & $4854(61.86 \%)$ & $13613(65.37 \%)$ & 29823(67.08\%) & $53220(67.19 \%)$ & $85227(66.36 \%)$ & 129478 \\
\hline $\begin{array}{l}\text { Caesarean } \\
\text { section }\end{array}$ & $68329(24.08 \%)$ & $517(17.38 \%)$ & 1374(17.51\%) & $3974(19.08 \%)$ & $9659(21.72 \%)$ & $18846(23.79 \%)$ & $33959(26.44 \%)$ & 702918 \\
\hline Missing & $927(0.33 \%)$ & $29(0.98 \%)$ & $55(0.70 \%)$ & $130(0.62 \%)$ & $194(0.44 \%)$ & $222(0.28)$ & $297(0.23 \%)$ & $2757(0$. \\
\hline
\end{tabular}

Table 2. Incidence of adverse maternal and perinatal outcome according to maternal age
All Maternal age (y) adolescents
$<=14 \quad 15$
16
17
18
19 e

\section{Matemal}

outcomes

\begin{tabular}{|c|c|c|c|c|c|c|c|c|c|}
\hline $\begin{array}{l}\text { Miscarriage } \\
\text { or abortion }\end{array}$ & 23463(82.7) & 636(213.9) & 1343(171.1) & 2706(129.9) & 4298(96.7) & 6293(79.4) & 8187(63.7) & 75183(36.1) & -0.36 \\
\hline TOP & 2635(9.3) & $137(46.1)$ & $221(28.2)$ & $401(19.3)$ & $488(11.0)$ & $633(8.0)$ & 755(5.9) & $7166(3.4)$ & -0.43 \\
\hline $\begin{array}{l}\text { Antepartum } \\
\text { hemorrhage }\end{array}$ & $2204(7.8)$ & $22(7.4)$ & $57(7.3)$ & 199(9.6) & $357(8.0)$ & $613(7.7)$ & $956(7.4)$ & 19404(9.3) & 0.06 \\
\hline $\begin{array}{l}\text { Postpartum } \\
\text { hemorrhage }\end{array}$ & $9164(32.3)$ & $92(30.9)$ & $263(33.5)$ & $663(31.8)$ & 1437(32.3) & $2540(32.1)$ & $4169(32.5)$ & 71594(34.4) & 0.02 \\
\hline $\begin{array}{l}\text { Puerperal } \\
\text { infection }\end{array}$ & $362(1.3)$ & $5(1.7)$ & $11(1.4)$ & $25(1.2)$ & $49(1.1)$ & $98(1.2)$ & $174(1.4)$ & $2221(1.1)$ & -0.06 \\
\hline Preeclampsia & $4824(17.0)$ & $31(10.4)$ & 158(20.1) & $339(16.3)$ & $735(16.5)$ & 1331(16.8) & 2230(17.4) & $35932(17.3)$ & 0.01 \\
\hline Eclampsia & $382(1.3)$ & $5(1.7)$ & $21(2.7)$ & $41(2.0)$ & $77(1.7)$ & $114(1.4)$ & $124(1.0)$ & $1136(0.5)$ & -0.35 \\
\hline $\begin{array}{l}\text { HELLP } \\
\text { syndrome }\end{array}$ & $128(0.5)$ & $0(0)$ & $5(0.6)$ & $5(0.2)$ & $28(0.6)$ & $38(0.5)$ & $52(0.4)$ & $726(0.3)$ & -0.1 \\
\hline GDM & 2784(9.8) & $16(5.4)$ & $56(7.1)$ & 177(8.5) & $365(8.2)$ & 753(9.5) & 1417(11.0) & $50177(24.1)$ & 0.42 \\
\hline PROM & 19159(67.5) & $125(42.0)$ & $417(53.1)$ & 1232(59.2) & $2862(64.4)$ & $5351(67.6)$ & 9172(71.4) & 175503(84.3) & 0.11 \\
\hline Severe anemia & $1813(6.4)$ & $13(4.4)$ & $62(7.9)$ & 139(6.7) & $340(7.6)$ & $481(6.1)$ & $778(6.1)$ & $9003(4.3)$ & -0.15 \\
\hline MNM & $1183(4.2)$ & $16(5.4)$ & $39(5.0)$ & $109(5.2)$ & $218(4.9)$ & $329(4.2)$ & $472(3.7)$ & $6107(2.9)$ & -0.15 \\
\hline $\begin{array}{l}\text { MMR during } \\
\text { hospitalization, } \\
\text { per } 100000 \\
\text { women }\end{array}$ & $23(8.1)$ & $0(0)$ & $0(0)$ & $1(4.8)$ & $6(13.5)$ & $7(8.8)$ & $9(7.0)$ & $154(7.4)$ & -0.03 \\
\hline
\end{tabular}

Perinatal

outcomes

\begin{tabular}{|c|c|c|c|c|c|c|c|c|c|}
\hline LBW & 19645(77.3) & 224(107.3) & 649(107.2) & 1771(102.7) & $3460(88.7)$ & $5641(79.1)$ & 7900(66.8) & $93459(47.0)$ & -0.22 \\
\hline $\begin{array}{l}\text { Preterm } \\
\text { delivery }\end{array}$ & 19784(77.9) & 253(121.2) & 688(113.7) & 1712(99.3) & $3506(89.9)$ & 5493(77.0) & 8132(68.7) & $106335(53.5)$ & -0.18 \\
\hline Stillbirth & $5300(20.4)$ & 219(94.9) & $392(60.8)$ & $733(40.8)$ & $974(24.4)$ & $1344(18.5)$ & 1638(13.7) & $15664(7.8)$ & -0.42 \\
\hline SGA & $39241(154.5)$ & $344(164.8)$ & 1149(189.8) & $3128(181.4)$ & $6620(169.8)$ & 11261(157.8) & $16739(141.5)$ & $200472(100.8)$ & -0.2 \\
\hline $\begin{array}{l}\text { Early } \\
\text { neonatal death }\end{array}$ & $584(2.3)$ & $20(9.6)$ & $25(4.1)$ & $57(3.3)$ & $126(3.2)$ & $134(1.9)$ & $222(1.9)$ & $2393(1.2)$ & -0.29 \\
\hline
\end{tabular}

TOP, terminate of pregnancy; TOP refers to induced labor at more than 28 weeks of gestation due to fetal or maternal causes.

GDM, gestational diabetes mellitus; PROM, premature rupture of membranes; MMR, maternal mortality ration; MNM, maternal near miss; LBW: low birth weig small-for-gestation-age. 
Table 3. Adjusted odds ratios and 95\% confidence interval of Adolescent pregnancies for adverse maternal and perinatal outcome

$\begin{array}{lll}\text { Adolescents } & \\ <18 & 18-19 & \text { Total }\end{array}$

Maternal outcomes

\begin{tabular}{|c|c|c|c|}
\hline Miscarriage or abortion & $1.25(1.07 \sim 1.46)$ & $1.03(0.95 \sim 1.13)$ & $1.08(0.97 \sim 1.20)$ \\
\hline TOP & $2.57(2.19 \sim 3.01)$ & $1.38(1.23 \sim 1.55)$ & $1.74(1.56 \sim 1.93)$ \\
\hline Antepartum hemorrhage & $0.96(0.85 \sim 1.08)$ & $0.90(0.84 \sim 0.96)$ & $0.92(0.85 \sim 0.98)$ \\
\hline Postpartum hemorrhage & $0.91(0.83 \sim 1.01)$ & 0.93(0.88 0.99) & $0.93(0.87 \sim 0.99)$ \\
\hline Puerperal infection & $1.00(0.78 \sim 1.27)$ & $1.22(1.03 \sim 1.44)$ & $1.16(0.99 \sim 1.36)$ \\
\hline Preeclampsia & $0.88(0.81 \sim 0.95)$ & $0.94(0.90 \sim 0.98)$ & $0.92(0.88 \sim 0.97)$ \\
\hline Eclampsia & $2.06(1.67 \sim 2.54)$ & 1.56(1.34 1.82) & $1.70(1.49 \sim 1.94)$ \\
\hline HELLP syndrome & $1.29(0.89 \sim 1.88)$ & $1.27(1.01 \sim 1.62)$ & $1.28(1.04 \sim 1.58)$ \\
\hline GDM & $0.54(0.48 \sim 0.60)$ & $0.62(0.58 \sim 0.67)$ & $0.60(0.56 \sim 0.65)$ \\
\hline PROM & $0.69(0.64 \sim 0.74)$ & $0.82(0.78 \sim 0.85)$ & $0.78(0.75 \sim 0.82)$ \\
\hline Severe anemia & $1.20(1.08 \sim 1.34)$ & 1.15(1.07 1.23) & 1.16(1.09 1.24) \\
\hline MNM & $1.22(1.05 \sim 1.41)$ & $1.14(1.05 \sim 1.25)$ & $1.16(1.07 \sim 1.27)$ \\
\hline Maternal death during hospitalization & $0.36(0.14 \sim 0.94)$ & $0.53(0.33 \sim 0.84)$ & $0.47(0.30 \sim 0.73)$ \\
\hline \multicolumn{4}{|l|}{ Perinatal outcomes } \\
\hline Stillbirth & $2.35(2.12 \sim 2.61)$ & $1.38(1.29 \sim 1.47)$ & 1.63(1.52 1.75) \\
\hline Premature delivery & 1.67(1.58 1.77) & $1.33(1.28 \sim 1.38)$ & $1.41(1.36 \sim 1.47)$ \\
\hline LBW & $1.63(1.55 \sim 1.72)$ & $1.38(1.33 \sim 1.43)$ & 1.44(1.39 1.50) \\
\hline SGA & 1.34(1.29 1.38) & $1.26(1.23 \sim 1.28)$ & $1.28(1.25 \sim 1.30)$ \\
\hline Early neonatal death & $1.92(1.60 \sim 2.30)$ & $1.23(1.08 \sim 1.40)$ & $1.40(1.24 \sim 1.59)$ \\
\hline \multicolumn{4}{|c|}{$\begin{array}{l}\text { TOP, terminate of pregnancy; TOP refers to induced labor at more than } 28 \text { weeks of gestation due to fetal or maternal causes.; GDM, gestational diabetes } \\
\text { mellitus; PROM, premature rupture of membranes; MNM, maternal near miss; LBW: low birth weight; SGA: small-for-gestation-age. }\end{array}$} \\
\hline
\end{tabular}

\section{Figures}


(a)

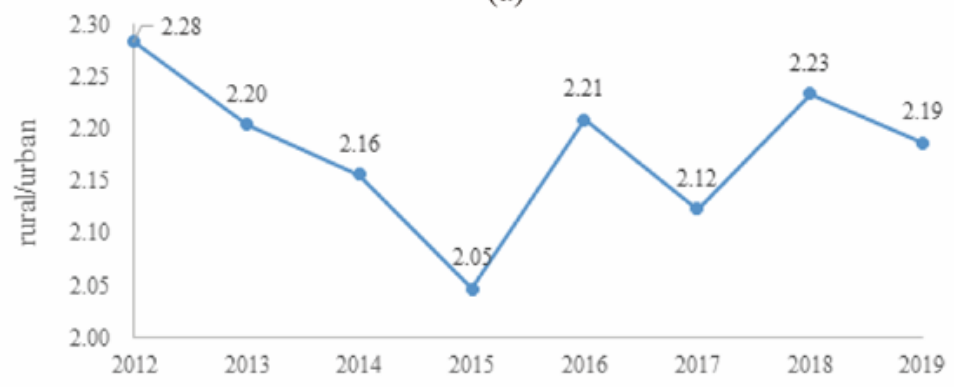

(b)

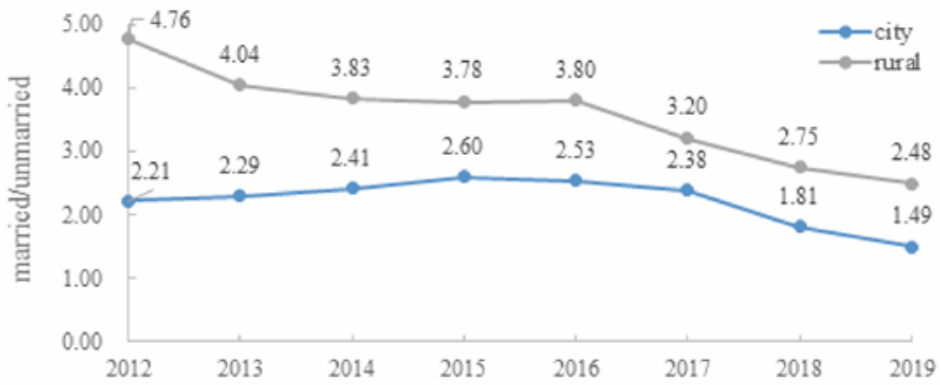

Figure 1

Changes for adolescent pregnancies in the proportion of urban divided by the rural areas (a) and the married divided by the unmarried (b) among $2012-2019$
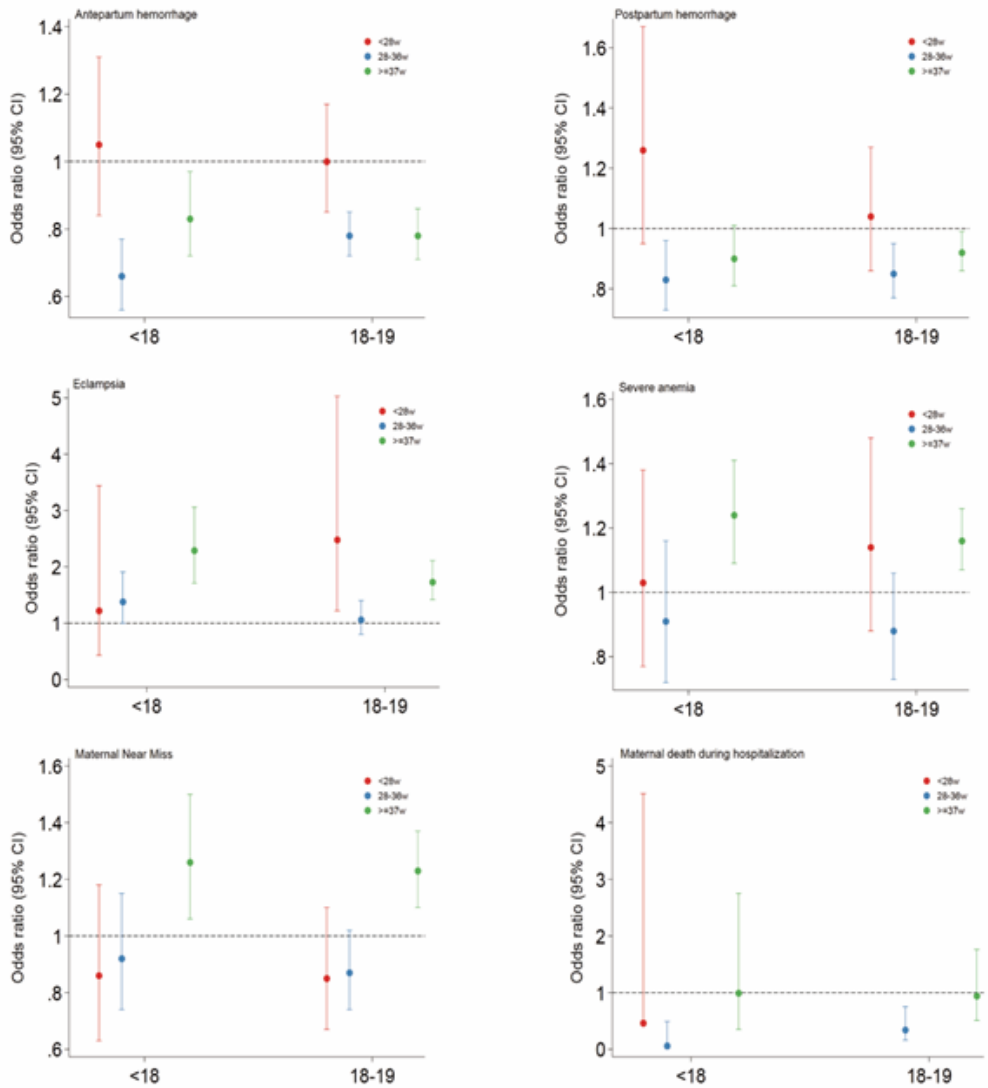

Figure 2

Adjusted odds ratios and $95 \%$ confidence interval of adolescent pregnancies for adverse maternal outcome stratified by gestational age

Page $11 / 12$ 

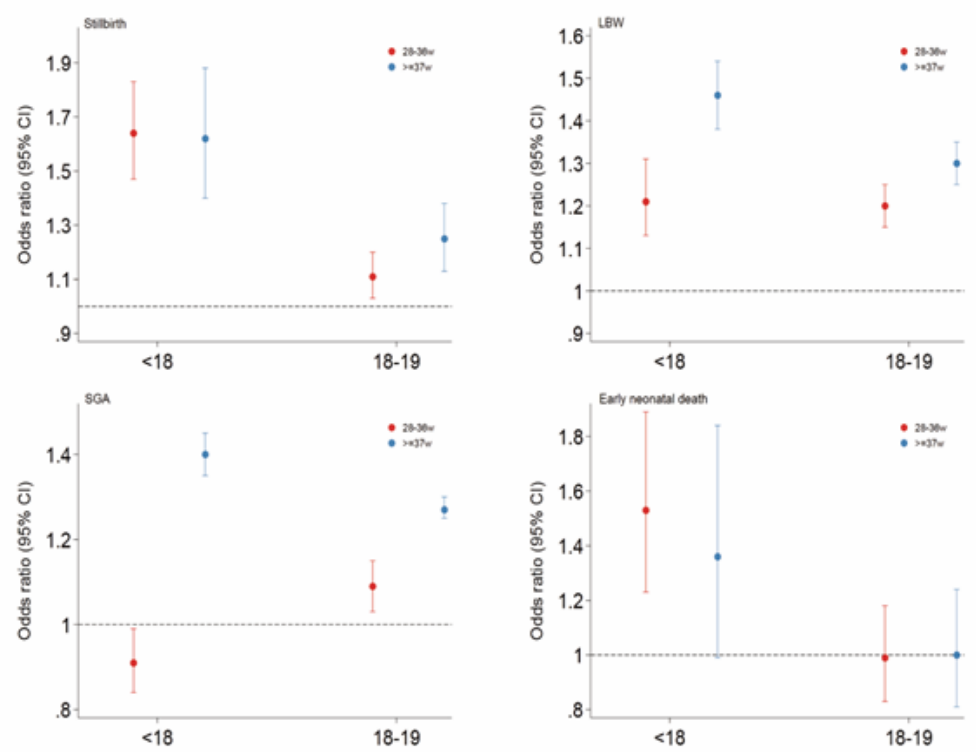

Figure 3

Adjusted odds ratios and $95 \%$ confidence interval of adolescent pregnancies for adverse perinatal outcome stratified by gestational age

\section{Supplementary Files}

This is a list of supplementary files associated with this preprint. Click to download.

- Additionalfile1.docx

- Supplementaryinformationfile.docx 